\section{BRAZIULIAN JOURNAL}

OF MEDICAL AND BIOLOGICAL RESHARCH

www.bjournal.com.br
ISSN 0100-879X

Volume 43 (10) 914-1009 October 2010

BIOMEDICAL SCIENCES

AND

CLINICAL INVESTIGATION

Braz J Med Biol Res, October 2010, Volume 43(10) 931-941

doi: 10.1590/S0100-879X2010007500091

Evaluation of anti-Wnt/ $\beta$-catenin signaling agents by pGL4-TOP transfected stable cells with a luciferase reporter system

K.A. Chuang, C.H. Lieu, W.J. Tsai, M.H. Wu,Y.C. Chen, J.F. Liao, C.C. Wang and Y.C. Kuo

The Brazilian Journal of Medical and Biological Research is partially financed by
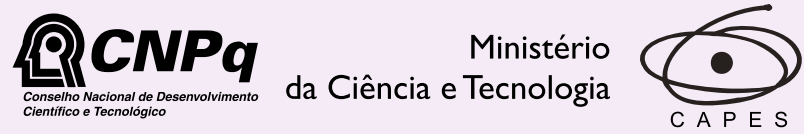

Ministério da Educação

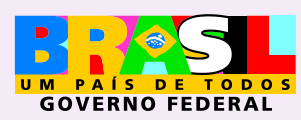

DFAPESP

Institutional Sponsors

Hotsite of proteomics metabolomics developped by:

$$
\text { an }
$$




\title{
Evaluation of anti-Wnt/ $\beta$-catenin signaling agents by pGL4-TOP transfected stable cells with a luciferase reporter system
}

\author{
K.A. Chuang ${ }^{1}$, C.H. Lieu ${ }^{1 *}$, W.J. Tsai ${ }^{2,3}$, M.H. Wu ${ }^{4}$, \\ Y.C. Chen ${ }^{4}$, J.F. Liao ${ }^{4}$, C.C. Wang ${ }^{5}$ and Y.C. Kuo ${ }^{6 *}$ \\ ${ }^{1}$ Department of Biotechnology and Laboratory Science in Medicine, School of Biomedical Science \\ and Engineering, National Yang-Ming University, Taipei, Taiwan, ROC \\ ${ }^{2}$ National Research Institute of Chinese Medicine, Taipei, Taiwan, ROC \\ ${ }^{3}$ Institute of Life Science, National Tai-Tung University, Taichung, Taiwan, ROC \\ ${ }^{4}$ Institute of Pharmacology, National Yang-Ming University, Taipei, Taiwan, ROC \\ ${ }^{5}$ School of Medicine, Fu-Jen University, Taipei, Taiwan, ROC \\ ${ }^{6}$ Institute of Life Science, Fu-Jen University, Taipei, Taiwan, ROC
}

\begin{abstract}
Refractory and relapsed leukemia is a major problem during cancer therapy, which is due to the aberrant activation of Wnt/ $\beta$ catenin signaling pathway. Activation of this pathway is promoted by wingless (Wnt) proteins and induces co-activator $\beta$-catenin binding to lymphoid enhancer factor (LEF)/T-cell factor protein (TCF). To provide a convenient system for the screening of antiWnt/ $\beta$-catenin agents, we designed a bi-functional pGL4-TOP reporter plasmid that contained 3X $\beta$-catenin/LEF/TCF binding sites and a selectable marker. After transfection and hygromycin B selection, HEK 293-TOP and Jurkat-TOP stable clones were established. The luciferase activity in the stable clone was enhanced by the recombinant Wnt-3A (rWnt-3A; 100-400 ng/mL) and GSK3ß inhibitor (2'Z,3'E)-6-bromoindirubin-3'-oxime (BIO; $5 \mu \mathrm{M})$ but was inhibited by aspirin ( $5 \mathrm{mM})$. Using this reporter model, we found that norcantharidin (NCTD; $100 \mu \mathrm{M}$ ) reduced $80 \%$ of rWnt-3A-induced luciferase activity. Furthermore, $50 \mu \mathrm{M}$ NCTD inhibited $38 \%$ of BIO-induced luciferase activity in Jurkat-TOP stable cells. Employing ${ }^{3} \mathrm{H}$-thymidine uptake assay and Western blot analysis, we confirmed that NCTD $(50 \mu \mathrm{M})$ significantly inhibited proliferation of Jurkat cells by $64 \%$, which are the dominant $\beta$-catenin signaling cells and decreased $\beta$-catenin protein in a concentration-dependent manner. Thus, we established a stable HEK 293-TOP clone and successfully used it to identify the Wnt/ $\beta$-catenin signaling inhibitor NCTD.
\end{abstract}

Key words: Cancer; Plasmids; Reporter assay; Screening; Wnt; $\beta$-catenin

\section{Introduction}

Constitutive activation of the wingless $(\mathrm{Wnt}) / \beta$-catenin signaling pathway has been reported to be associated with carcinogenesis and to correlate with both shortened relapsefree survival and overall survival in leukemia patients (1). Mutation of the phosphorylation sites in the $\mathrm{NH}_{2}$-terminal domain of $\beta$-catenin has been observed in T-cell malignancies (2). Increased expression of Wnt ligands or frizzled (Fz) receptors has been described in acute myeloid leukemia (3). Autocrine $W n t / \beta$-catenin signaling would also seem to contribute to leukemic cancer cell proliferation $(2,3)$. These lines of evidence support a crucial role for $\mathrm{Wnt} / \beta$-catenin signaling in the maintenance of leukemia. Although chemo- therapy and radiotherapy do help long-term patient survival, relapse is still a major cause of death in many kinds of cancer (4). Recently, many studies have indicated that the cancer stem/progenitor cells from patients with leukemia, colon cancer, or skin cancer inappropriately express Wnt/ $\beta$ catenin signaling. These cells possess self-renewal ability like stem cells and are responsible for relapse even under Imatinib treatment (5-8). Thus, blocking the Wnt/ $\beta$-catenin signaling may help reduce the frequency of relapses in cancer patients.

Nonsteroidal anti-inflammatory drugs (NSAIDs) such as aspirin and indomethacin can potentially act as therapeutic

Correspondence: Y.C. Kuo, LS212, Laboratory of Molecular Pharmacology, Institute of Life Science, Fu-Jen University, No. 510, Chung Cheng Rd., Hsinchuang, Taipei Hsien 242, Taiwan (ROC). Fax: +886-2-2905-2193; E-mail: 021553@mail.fju.edu.tw

*These authors contributed equally to this study.

Received May 21, 2010. Accepted August 19, 2010. Available online September 10, 2010. Published October $18,2010$. 
agents to suppress $\beta$-catenin activity (9). Unfortunately, NSAIDs also have an inhibitory effect on cyclooxygenase-1 (COX-1) and COX-2 activity and cause gastrointestinal bleeding. Thus, it becomes important to search for other $W n t / \beta$-catenin signaling inhibitors that do not have severe side effects. Lepourcelet et al. (10) have reported six natural products, ZTM00090, PKF118-310, PKF118-744, PKF115584, PKF222-815, and CGP049090, that seem to abolish $\beta$-catenin and T-cell factor (TCF) protein-protein interaction. These compounds significantly decreased cyclin D1 gene expression and inhibited cell proliferation in colon cancer cells. Employing a transient reporter assay in a cell-based system, one small molecule, ICG-001, was shown to block the formation of the $\beta$-catenin/CBP complex and to arrest cancer cell proliferation. This molecule also attenuated the growth of xenograft colon cancers in mice (11). Since the development of new drugs has been limited, we suggest that searching for new antagonists of $\mathrm{Wnt} / \beta$-catenin signaling would seem to require a high-throughput assay.

The hallmark of the $\mathrm{Wnt} / \mathrm{\beta}$-catenin signaling pathway is $\beta$-catenin, which acts as a multiple function protein including adhesion to the cell membrane and transcription activation in the nucleus (12). In the absence of Wnt proteins, little $\beta$-catenin is present in the cytoplasm; this is due to the fact that $\beta$-catenin interacts with glycogen synthase kinase $3 \beta$

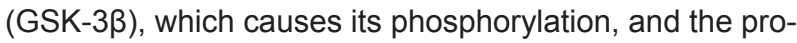
tein is then degraded by the ubiquitin-proteasome system (13). When Wnt proteins bind to Fz receptors, GSK-3 $\beta$ activity is disrupted and $\beta$-catenin escapes degradation. The unphosphorylated $\beta$-catenin then translocates into the nucleus, binds to the lymphoid enhancer factor (LEF)/ TCF transcription factors, and turns on downstream gene expression including c-myc and cyclin D1, which regulate cell proliferation and apoptosis $(14,15)$.

In the present study, we cloned the LEF/TCF binding sequences into a pGL4.3 luciferase reporter plasmid, which was part of an antibiotic-resistant plasmid. This new construct was transfected into human embryonic kidney (HEK) 293 and human Jurkat leukemic T cells to establish the HEK 293-TOP and Jurkat-TOP stable reporter cell lines. The activities of these cell lines were indicated by luciferase activity induced by recombinant Wnt-3A (rWnt-3A) protein and (2'Z,3'E)-6-bromoindirubin-3'-oxime (BIO). We also used the cell lines for drug screening and discovered the norcantharidin (NCTD) that inhibited the activation of the Wnt/ $\beta$-catenin signaling pathway in both HEK 293-TOP and Jurkat-TOP cells and reduced the $\beta$-catenin levels and cell proliferation in Jurkat T cells.

\section{Material and Methods}

\section{Material}

$\mathrm{BIO}$, 1-methyl-BIO (MeBIO), lithium chloride ( $\mathrm{LiCl})$ and $\mathrm{N}$-(2-methyl-4-nitro)-2,4-dichlorosulfonamide (FH535) were purchased from Merck (Germany). NCTD $\left(\mathrm{C}_{8} \mathrm{H}_{8} \mathrm{O}_{4}\right.$; MW
168) was synthesized as described previously (16). Mouse rWnt-3A was obtained from R\&D (USA). Mouse monoclonal antibodies raised against human $\beta$-catenin (cat. No. sc7963), $\beta$-actin (cat. No. sc-47778) and GSK-3 $\beta$ (cat. No. 610201) were purchased from Santa Cruz (USA) and BD Bioscience (USA). Goat anti-mouse IgG conjugated with horseradish peroxidase was purchased from Pierce (USA). Other reagents were obtained from Sigma (USA).

\section{Cell culture}

HEK 293 (FIRDI, Taiwan), L cells (FIRDI), and L Wnt3 A cells (ATCC, USA) were cultured in DMEM (Invitrogen, USA). Jurkat cells (FIRDI) were cultured in RPMI-1640 medium (Invitrogen). Both media were supplemented with $10 \%$ fetal bovine serum (FBS), $2 \mathrm{mM}$ L-glutamine, 0.1 $\mathrm{mM}$ sodium pyruvate, $100 \mathrm{U} / \mathrm{mL}$ penicillin, and $100 \mu \mathrm{g} /$ $\mathrm{mL}$ streptomycin. HEK 293-TOP/FOP and Jurkat-TOP/ FOP cells were regularly maintained in selected medium containing 500 and $1000 \mu \mathrm{g} / \mathrm{mL}$ hygromycin B, respectively. All cells were incubated at $37^{\circ} \mathrm{C}$ in a humidified atmosphere under $5 \% \mathrm{CO}_{2}$. Wnt-3A and control conditioned media were prepared according to ATCC recommendation.

\section{Generation of pGL4-TOP/FOP reporter plasmids}

Two primers, TOP265-F: 5'GTCAGATCTCTTAATATG CGAAGTGGACC3' and TOP265-R: 5'CGTGGTACCGT AACGCCAGGGTTTTCC3', were designed from the sequence data of the TOPFLASH plasmid and used to amplify either the TOP (wild-type 3X LEF/TCF binding sites; $265 \mathrm{bp}$ ) or the FOP elements (mutant 3X LEF/TCF binding sites; 255 bp) from TOPFLASH or FOPFLASH (Upstate Biotechnology, USA) by the polymerase chain reaction (PCR). The TOP and FOP elements were amplified using the following program: $94^{\circ} \mathrm{C}$ for $10 \mathrm{~min}$, followed by 30 cycles of $94^{\circ} \mathrm{C}$ for $1 \mathrm{~min}, 54^{\circ} \mathrm{C}$ for $1 \mathrm{~min}, 72^{\circ} \mathrm{C}$ for $30 \mathrm{~s}$, then finally $4^{\circ} \mathrm{C}$ for 10 $\min$. The amplified products were cloned into the pGL4.3 luciferase reporter plasmid (Promega, USA) using the Bg/ll and $K p n l$ cleavage sites and the two successfully created ampicillin-selected plasmids were called pGL4-TOP and pGL4-FOP (Figure 1A).

\section{Establishment of the HEK 293-TOP/FOP and Jurkat-TOP/FOP reporter cell lines}

The $0.8 \mu \mathrm{g}$ pGL4-TOP (or FOP) reporter plasmid was transfected into HEK 293 cells $\left(2 \times 10^{5}\right)$ with Lipofectamin ${ }^{T M}$ 2000 (Invitrogen) according to manufacturer instructions. The transfected cells were selected in medium containing $500 \mu \mathrm{g} / \mathrm{mL}$ hygromycin B (MDBio, Taiwan) for 3 weeks to obtain a stable clone. Medium was replaced with fresh medium every 3 days. At the end of 3 weeks, the surviving cells were diluted in a 96-well plate (Nunclon, Denmark) and a single cell-derived clone was selected and cultured to give a stable cell line in the presence of hygromycin B. These stable clones were called HEK 293-TOP or HEK 293-FOP. Jurkat cells were transfected with $3 \mu \mathrm{g}$ pGL4-TOP/FOP 
by electroporation using a MicroPorator system (MP-100; Digital Bio Technology, Korea) according to manufacturer instructions. The stable cells were selected in medium containing $1500 \mu \mathrm{g} / \mathrm{mL}$ hygromycin B.

\section{Luciferase assay}

HEK 293-TOP cells $\left(1 \times 10^{4}\right)$ or Jurkat-TOP/FOP $(2 \times$ $10^{4}$ ) cells were seeded into 96 -well plates and incubated in medium with $10 \%$ FBS for one day. The cells were then stimulated with rWnt-3A $(100,200,400 \mathrm{ng} / \mathrm{mL}), \mathrm{L}$ Wnt-3A conditioned medium (Wnt-3ACM), BIO, or LiCl. After incubation for the indicated times, total cell lysates were extracted with $1 \mathrm{X}$ reporter lysis buffer (Promega) and $10 \mu \mathrm{g}$ total cell proteins were used to determine luciferase activity by the Luciferase Assay System (Promega) using a Microplate Luminometer (Berthold, Germany).

\section{Proliferation assay}

Jurkat cells $\left(2 \times 10^{4} /\right.$ well) were cultured in a 96-well plate for $24 \mathrm{~h}$. Various concentrations of NCTD (12.5 to $50 \mu \mathrm{M}$ ) were added to the cells and the plates were incubated in a $5 \% \mathrm{CO}_{2}$-air humidified atmosphere at $37^{\circ} \mathrm{C}$ for 2 days. Subsequently, tritiated thymidine $(1 \mu \mathrm{Ci} /$ well; New England Nuclear, USA) was added to each well. After 16-h incubation, the cells were harvested onto glass-fiber filters with an automatic harvester (Multimash 2000, Dynatech, UK). The radioactivity of the filters was measured with a scintillation counter.

\section{Western blot analysis}

HEK 293-TOP/FOP cytosolic proteins were examined by Western blot analysis. Proteins were separated by $10 \%$ SDS-PAGE and transferred to an Immobilon-P PVDF membrane (Millipore, USA). Antibodies against $\beta$-actin $(1: 1000), \beta$-catenin $(1: 1000)$ and GSK-3 $\beta$ (1:1000) were used for protein detection. The specific reactive proteins were detected by an enhanced chemiluminescence method that employed rabbit anti-mouse IgG conjugated with horseradish peroxidase. The immunoblots were visualized with the immobilon Western chemiluminescent HRP substrate (Millipore).

\section{RNA extraction and RT-PCR}

Total RNA was isolated from Jurkat cells with RNA$\mathrm{Bee}^{\mathrm{TM}}$ (Tel-Test, USA) according to manufacturer instructions. For cDNA synthesis, $1 \mu \mathrm{g}$ total RNA was added to a $10-\mu \mathrm{L}$ reaction volume, including reaction buffer, oligo dT, dNTP and reverse transcriptase and the procedure was used according to manufacturer instructions. The primer sequences used to detect the GAPDH and $\beta$-catenin gene CTNNB1 were as follows: GAPDH: TGAAGGTCGGAGTCAACGGATT TGGT (sense) and CATGTGGGCCATGAGGTCCACCAC (anti-sense); CTNNB1:ACTCTAGGAATGAAGGTGTGGC (sense) and AGTGTGTCAGGCACTTTCTGAG (antisense). PCR was carried out using the following procedure: $94^{\circ} \mathrm{C}$ for $10 \mathrm{~min}$, followed by 30 cycles of $94^{\circ} \mathrm{C}$ for $1 \mathrm{~min}$, $60^{\circ} \mathrm{C}$ for $1 \mathrm{~min}, 72^{\circ} \mathrm{C}$ for $30 \mathrm{~s}$, and finally $4^{\circ} \mathrm{C}$ for $10 \mathrm{~min}$. After reaction, the amplified products were run on a $2 \%$ agarose gel.

\section{Statistical analysis}

Data are reported as means \pm SD of at least three experiments. The differences between groups were determined by the Student $t$-test, with the level of significance set at $P<0.05$.

\section{Results}

\section{Generation of the HEK 293-TOP/FOP stable cell lines for drug screening}

The TOPFLASH plasmid contains three LEF/TCF binding sites (17). In order to establish a Wnt/ß-catenin signaling-response stable cell line for drug screening, we amplified the TOP element that contained three LEF/TCF binding sites from TOPFLASH and inserted them into the pGL4.3 reporter plasmid that contains a hygromycin B phosphotransferase coding gene (Hygr) and a luciferase reporter gene. This new constructed plasmid was named pGL4-TOP (Figure 1A). The integrity of the three LEF/TCF sequences was confirmed by DNA sequence analysis. No mutations of binding sequences were detected (data not shown). In addition, the pGL4-FOP, which contained three mutated LEF/TCF binding sites derived from the FOPFLASH plasmid, was constructed as a negative control. These new bi-functional reporter constructs pGL4-TOP and pGL4-FOP can be used to create stable clones using hygromycin $B$ selection without co-transfection with a plasmid containing a selectable marker. Therefore, the pGL4-TOP/FOP reporter plasmids were transfected into HEK 293 cells and expression of the Hygr gene protected the cells, HEK 293-TOP and HEK 293-FOP, from antibiotic treatment.

\section{Luciferase activity of HEK 293-TOP cells was activated} by Wnt-3A proteins and a specific inhibitor of GSK-3 $\beta$.

It is well known that Wnt proteins activate the downstream signaling by stabilization of $\beta$-catenin and enhance target gene expression in the nucleus. We evaluated basal and inducible levels of $\beta$-catenin signaling in HEK 293TOP by measuring protein expression of $\beta$-catenin and by measuring the transcriptional activity of the reporter. HEK 293-TOP stable cells were cultured in the presence of 100,200 , and $400 \mathrm{ng} / \mathrm{mL} \mathrm{rWnt}-3 \mathrm{~A}$ for $24 \mathrm{~h}$. The cell proteins were then extracted from the cells and subjected to Western blotting and a luciferase assay. As shown in Figure $1 \mathrm{~B}, \beta$-actin was used as a loading control and rWnt$3 A$ stimulation increased the levels of $\beta$-catenin protein in a dose-dependent manner. Comparison with the control group (medium only), the vehicle ( $0.1 \%$ BSA) did not affect $\beta$-catenin protein expression. When stimulated with 100 , 200 and $400 \mathrm{ng} / \mathrm{mL}$ rWnt-3A, luciferase activities from HEK 
293-TOP significantly increased by 1.3 -fold $(P<0.05)$, 1.5 fold $(P<0.01)$, and 2.1 -fold $(P<0.01)$, respectively (Figure $1 C)$. Furthermore, there was a 2.5 -fold increase $(P<0.001)$ of luciferase activity upon stimulation with $50 \%$ (v/v) Wnt-3A CM in HEK 293-TOP cells. HEK 293-FOP cells were not affected (Figure 2A). These results indicate that Wnt-3A specifically increased the amount of $\beta$-catenin protein and induced luciferase activity in HEK 293-TOP stable cells.

GSK-3 $\beta$, a negative regulator of the $\mathrm{Wnt} / \beta$-catenin signaling, is involved in the TCF-mediated transcriptional pathway and its inhibitor has been used as a pharmacological agent to activate this pathway (18). To confirm the specificity of Wnt/ $\beta$-catenin signaling induction, a specific inhibitor of GSK-3 $\beta$, BIO $(5 \mu \mathrm{M})$, was incubated with HEK 293-TOP cells in the presence of rWnt-3A (400 ng/mL) for $24 \mathrm{~h}$ and luciferase activity was then determined. As shown in Figure 2B, neither the vehicle for rWnt-3A $(0.1 \% \mathrm{BSA})$ nor the vehicle for $\mathrm{BIO}(0.05 \%$ DMSO) affected luciferase activity in HEK 293-TOP cells. However, both rWnt-3A and $\mathrm{BIO}$ activated the luciferase reporter by 2.6 -fold $(P<0.001)$ and 4.9 -fold $(P<0.001)$, respectively. MeBIO is an analog of $\mathrm{BIO}$ that does not inhibit GSK-3 $\beta$ activity. MeBIO $(5 \mu \mathrm{M})$ alone did not affect the luciferase activity. When HEK 293TOP cells were co-treated with rWnt-3A and MeBIO, MeBIO did not change the stimulatory effect of $r W n t-3 A$ on luciferase activity. However, an additive effect was observed in the cells treated with $\mathrm{BIO}$ and rWnt-3A $(P<0.01)$. As shown in Figure $2 \mathrm{D}$, while BIO did not affect GSK-3 $\beta$ protein expression, it increased the levels of $\beta$-catenin in HEK 293-TOP cells in a dose-dependent manner. On the other hand, we also used another GSK-3 $\beta$ inhibitor, $\mathrm{LiCl}$, to confirm the HEK 293-TOP response. As shown in Figure 2C, $\mathrm{LiCl}(20$ $\mathrm{mM}$ ) also activated the luciferase reporter by 10.9- and 4.9fold in the presence or absence of rWnt-3A, respectively. These results confirmed that HEK 293-TOP cells faithfully responded to the effects of rWnt-3A and the GSK-3 $\beta$ inhibitors during canonical Wnt/ $\beta$-catenin signaling.

\section{Aspirin and NCTD inhibit rWnt-3A-induced luciferase activity in HEK 293-TOP cells}

According to the report of Cho et al. (19), aspirin is able to decrease Wnt-3A CM-induced luciferase activity in HEK 293 cells. To determine whether HEK 293-TOP could be used as a drug screening platform, HEK 293-TOP cells were incubated with aspirin in the presence of rWnt$3 A(400 \mathrm{ng} / \mathrm{mL})$ and luciferase activity was analyzed. As shown in Figure 3A, rWnt-3A induced a 4.6-fold increase in luciferase activity $(P<0.01)$, while the vehicle $(0.1 \%$ BSA) did not affect activity. In contrast, treatment with 1.25 , 2.5 , and $5 \mathrm{mM}(\mathrm{P}<0.05)$ aspirin decreased the luciferase activity of the rWnt-3A-induced cells in a dose-dependent manner. Therefore, we predicted that the HEK 293-TOP cell line could be applied to screen potential Wnt/ $\beta$-catenin signaling blockers.

Thus, we collected several synthetic compounds or

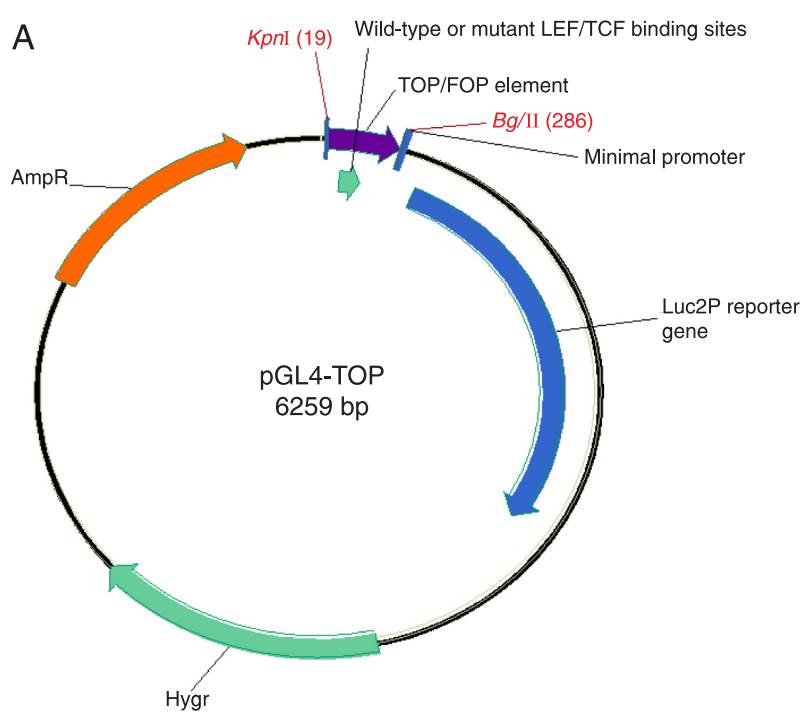

B
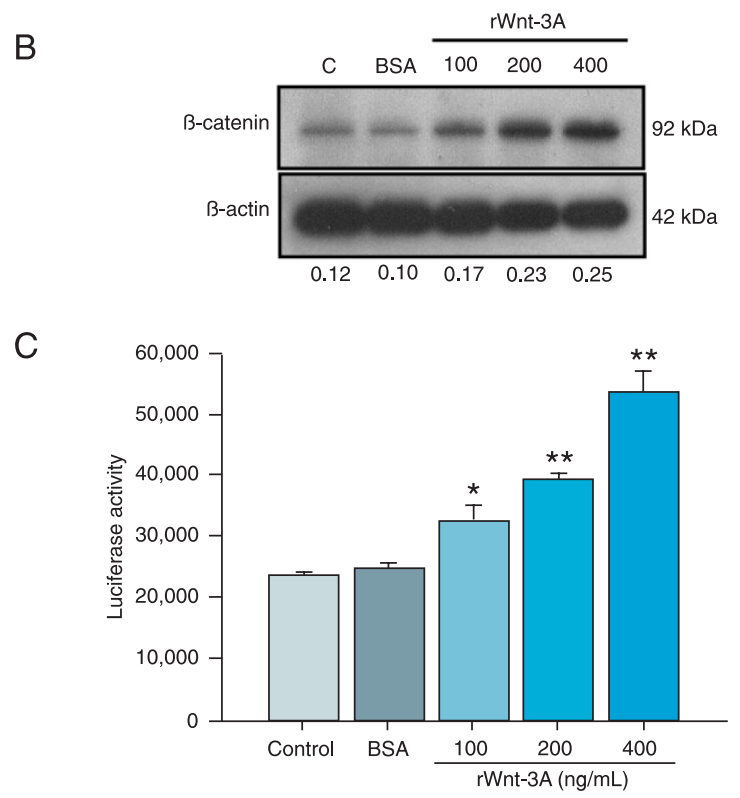

Figure 1. Map of the pGL4-TOP/FOP reporter plasmids and effects of rWnt-3A on $\beta$-catenin protein levels and luciferase activities in HEK 293-TOP stable cells. A 265-bp fragment containing the 3X LEF/TCF elements (19-286 bp) was amplified from TOPFLASH and FOPFLASH by PCR and inserted into the pGL4.3 reporter plasmid. The pGL4-TOP/FOP plasmid map was drawn with the Vector NTI software. LEF = lymphoid enhancer factor; TCF = T-cell factor protein; AmpR = beta-lactamase coding region; Hygr = hygromycin $\mathrm{B}$ coding region. HEK 293-TOP cells $\left(1 \times 10^{4}\right)$ were seeded into a 96-well plate for $24 \mathrm{~h}$ and then treated with medium $(\mathrm{C})$, BSA $(0.1 \%)$ or the indicated concentrations of rWnt-3A $(100,200,400 \mathrm{ng} / \mathrm{mL})$ for another $24 \mathrm{~h}$. Total cell proteins were collected and subjected to Western blotting $(B)$ and the luciferase assay $(C)$. The ratios of $\beta$-catenin to $\beta$-actin proteins are shown at the bottom of Panel B. Each bar in Panel $C$ is the mean $\pm S D$ of three independent experiments. ${ }^{*} P<0.05$, ${ }^{* \star} \mathrm{P}<0.01$ vs cells treated with $0.1 \%$ BSA (Student $t$-test). 
natural products for screening. We analyzed the effects of these compounds $(100 \mu \mathrm{M})$ on luciferase activity in HEK 293-TOP cells induced by Wnt-3A CM and calculated their inhibitory activities. As shown in Figure 3B, one of these compounds, compound 12 (NCTD), had an $80 \%$ inhibitory activity on luciferase activity in HEK 293-TOP stimulated with Wnt-3A CM. The specific inhibitory effect of NCTD on the Wnt/ $\beta$-catenin signaling was determined with HEK 293-TOP and HEK 293-FOP cells treated with Wnt-3A CM (Figure 3C). After stimulation with Wnt-3A CM, luciferase activity was induced in HEK 293-TOP cells but not in HEK $293-F O P$ cells. The vehicle $(0.05 \%$ DMSO) did not affect the luciferase activity of either HEK 293-TOP or HEK 293FOP cells. Furthermore, NCTD had little or no effect on luciferase activity in HEK 293-FOP cells. By contrast, NCTD significantly impaired luciferase activity in HEK 293-TOP cells in a concentration-dependent manner. As shown in Figure 3D, rWnt-3A was also used to stimulate the cells and to confirm the inhibitory activity of NCTD. When compared to the BSA-treated group, rWnt-3A induced luciferase activity by 3.9 -fold $(P<0.01)$ and NCTD inhibited luciferase activity in a concentration-dependent manner $(P<0.001)$.
These results indicate that potential Wnt/ $\beta$-catenin signaling inhibitors such as NCTD could be detected by the HEK 293-TOP reporter system.

\section{Luciferase activity of Jurkat-TOP cells was activated by Wnt-3A proteins and BIO inhibitor}

It has been reported that Jurkat cells express high levels of Wnt/ $\beta$-catenin signaling and play an important role in Jurkat cell proliferation (20). To examine whether activation of $W n t / \beta$-catenin signaling in a leukemic cancer cell line was blocked by NCTD, we established the Jurkat-TOP and Jurkat-FOP stable cells by pGL4-TOP and pGL4-FOP transfection, respectively. The stable Jurkat-TOP/FOP cells were stimulated with 100, 200, and $400 \mathrm{ng} / \mathrm{mL} \mathrm{rWnt}-3 \mathrm{~A}$ for $24 \mathrm{~h}$. As shown in Figure 4A, rWnt-3A stimulation increased the levels of $\beta$-catenin protein in both Jurkat-TOP and Jurkat-FOP stable cells. The vehicle $(0.1 \%$ BSA) did not affect $\beta$-catenin protein expression in either stable cell lines. Furthermore, rWnt-3A (100, 200, and $400 \mathrm{ng} / \mathrm{mL})$ significantly induced luciferase activities in Jurkat-TOP by 1.3-fold $(P<0.05)$, 1.6-fold $(P<0.01)$, and 1.8-fold $(P<$ $0.01)$, respectively. In contrast, the rWnt-3A-mediated in-

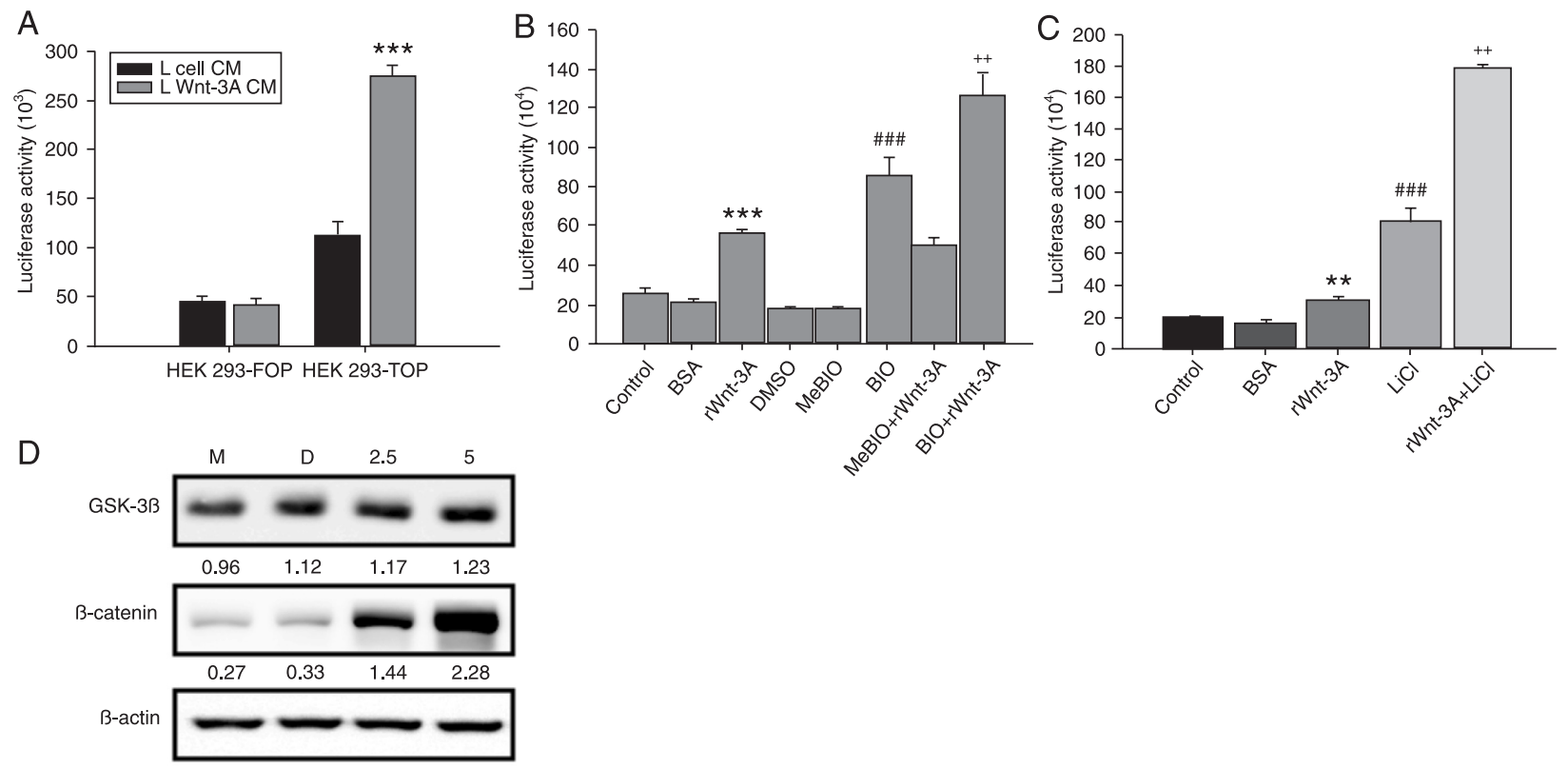

Figure 2. Effects of Wnt-3A proteins on luciferase activities in HEK 293-TOP/FOP stable cells treated or not with BIO or LiCl. A, HEK 293-TOP/FOP cells $\left(1 \times 10^{4}\right)$ were seeded into a 96-well plate for $24 \mathrm{~h}$ and then treated with $\mathrm{L}$ cell conditioned medium (CM; control) or $50 \%(\mathrm{v} / \mathrm{v}) \mathrm{L}$ Wnt-3A CM for another $24 \mathrm{~h}$. Total cell proteins were collected and subjected to the luciferase assay. ${ }^{* * *} \mathrm{P}<0.001 \mathrm{vs}$ HEK 293-TOP treated with L cell CM (Student $t$-test). B and C, HEK 293-TOP cells $\left(1 \times 10^{4}\right)$ were seeded into a 96-well plate for 24 h. The cells were stimulated or not with rWnt-3A $(400 \mathrm{ng} / \mathrm{mL})$ in the presence or absence of BIO $(5 \mu \mathrm{M})$ or $\mathrm{MeBIO}(5 \mu \mathrm{M})$ or LiCl $(20$ $\mathrm{mM}$ ) for $24 \mathrm{~h}$. Total cell proteins were extracted and the luciferase activities were determined. Each bar is the mean \pm SD of three independent experiments. ${ }^{* *} \mathrm{P}<0.01,{ }^{* * *} \mathrm{P}<0.001$ vs BSA $(0.1 \%)$ group; \#P $<0.01$, \#\#P $<0.001$ vs DMSO $(0.1 \%)$ or control (medium) group; ${ }^{++} \mathrm{P}<0.01$ vs BIO or $\mathrm{LiCl}$ group (Student $t$-test). $D$, HEK 293-TOP cells $\left(1 \times 10^{4}\right)$ were seeded into a 96 -well plate for $24 \mathrm{~h}$ and stimulated with BIO $(2.5$ and $5 \mu \mathrm{M})$ for another $24 \mathrm{~h}$. Finally, total cell proteins were extracted and subjected to Western blotting. The ratios of $\beta$-catenin or GSK-3 $\beta$ to $\beta$-actin proteins are shown in the bottom panel. $\mathrm{BIO}=\left(2^{\prime} Z, 3^{\prime} E\right)$-6-bromoindirubin-3'-oxime. Lane $\mathrm{M}=$ medium; lane D = DMSO $(0.1 \%)$. 
A
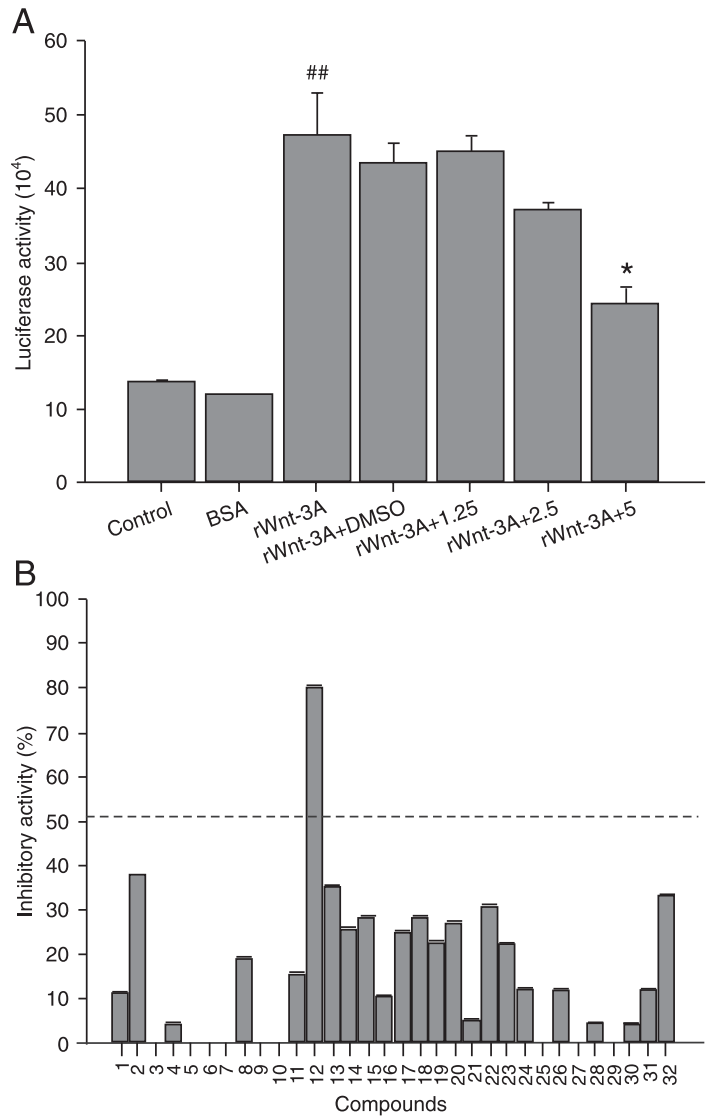

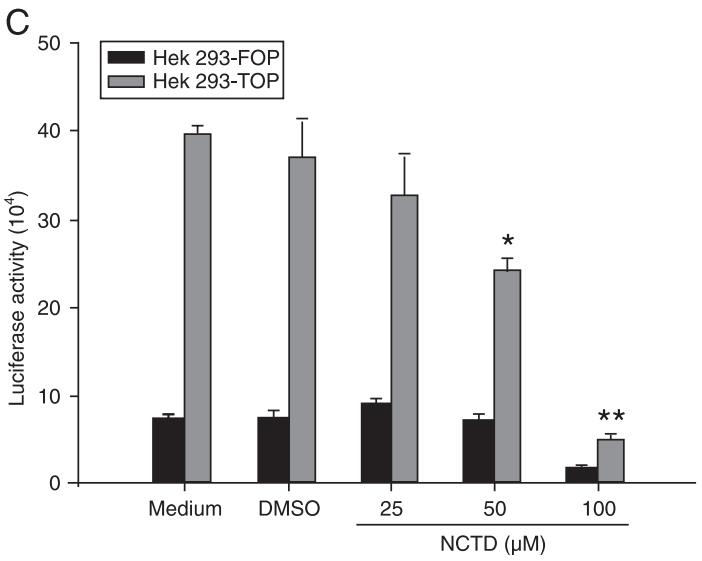

$\mathrm{D}$

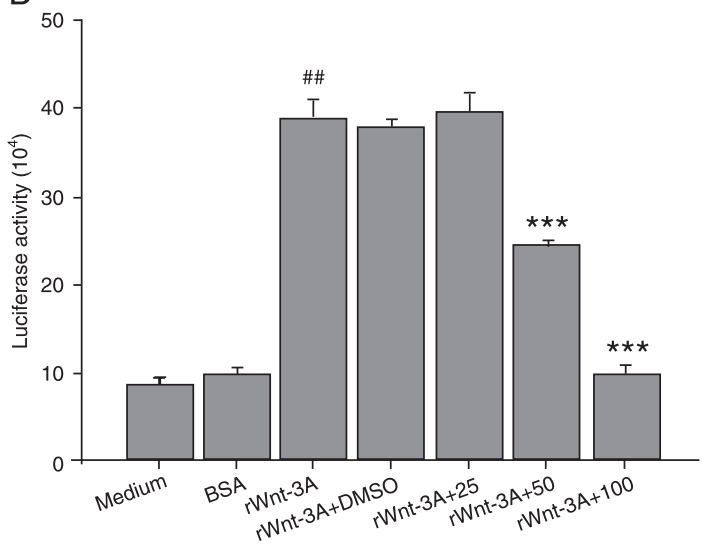

Figure 3. Effects of aspirin and 32 other compounds on luciferase activity in HEK 293-TOP cells induced with Wnt-3A proteins. $A, B$, HEK 293 -TOP cells $\left(1 \times 10^{4}\right)$ were seeded into a 96 -well plate for $24 \mathrm{~h}$ and then stimulated with $\mathrm{rWnt}-3 \mathrm{~A}$ or Wnt-3A CM in the presence of aspirin $(1.25,2.5$, and $5 \mathrm{mM})$ or the test agents $(100 \mu \mathrm{M})$ for $24 \mathrm{~h}$. Total cell proteins were extracted and luciferase activity was determined. C, HEK 293-TOP/FOP cells $\left(1 \times 10^{4}\right)$ were plated into a 96-well plate and then stimulated with Wnt-3A CM in the presence of $\operatorname{NCTD}(25,50,100 \mu \mathrm{M})$. D, HEK 293-TOP cells were cultured with rWnt-3A $(400 \mathrm{ng} / \mathrm{mL})$ and various concentration of $\operatorname{NCTD}(25,50,100 \mu \mathrm{M})$ for $24 \mathrm{~h}$. Finally, total cell proteins were collected and subjected to luciferase assay. Each bar indicates the mean \pm SD of three independent experiments. NCTD $=$ norcantharidin. ${ }^{*} \mathrm{P}<0.05,{ }^{* *} \mathrm{P}<0.01,{ }^{* * *} \mathrm{P}<0.001$ vs HEK $293-\mathrm{TOP}$ cells treated with Wnt-3A and $0.1 \%$ DMSO. ${ }^{\# P}<$ 0.01 vs cells treated with $0.1 \%$ BSA (Student $t$-test).

crease in LEF/TCF luciferase activities had no significant effect on Jurkat-FOP cells. We also observed if GSK-3 $\beta$ inhibitor was able to activate luciferase activities in JurkatTOP/FOP cells. As shown in Figure 4B, while the vehicle (DMSO) did not affect $\beta$-catenin protein expression, BIO markedly increased the levels of $\beta$-catenin protein in both Jurkat-TOP and Jurkat-FOP stable cells at $12 \mathrm{~h}$ postactivation. For the reporter assay, the relative luciferase activities of Jurkat-TOP cells were 20 -fold higher than those of Jurkat-FOP cells. After BIO treatment, the transcriptional activity of luciferase in Jurkat-TOP cells was increased in a dose-dependent manner (2.2-, 3.1- and 4.0-fold; $\mathrm{P}<0.001)$. However, these results were not due to the decrease of GSK-3 $\beta$ protein expression in BIO-treated Jurkat-TOP cells (Figure 4C). Taken together, these results show that Jurkat-
TOP cells faithfully responded to the rWnt-3A protein and to the GSK-3 $\beta$ inhibitor.

\section{NCTD inhibited $\beta$-catenin/LEF-mediated luciferase activity in Jurkat-TOP cells and correlated with a reduction of cell proliferation and the level of $\beta$-catenin proteins}

To elucidate whether NCTD had an inhibitory effect on $\mathrm{Wnt} / \mathrm{\beta}$-catenin signaling in leukemic cancer cells, BIO and various concentrations of NCTD were added to the Jurkat-TOP/FOP cells for $12 \mathrm{~h}$. As shown in Figure 5A, treatment with $50 \mu \mathrm{M}$ NCTD significantly decreased $38 \%$ of the luciferase activity in BIO-treated cells. In contrast, the vehicle (DMSO) did not affect relative luciferase activity. The positive control, $\beta$-catenin/TCF inhibitor FH535 (15 
A

C BSA $\frac{\text { rWnt-3A }}{100200400}$ C BSA $\frac{\text { rWnt-3A }}{100200 \quad 400}$
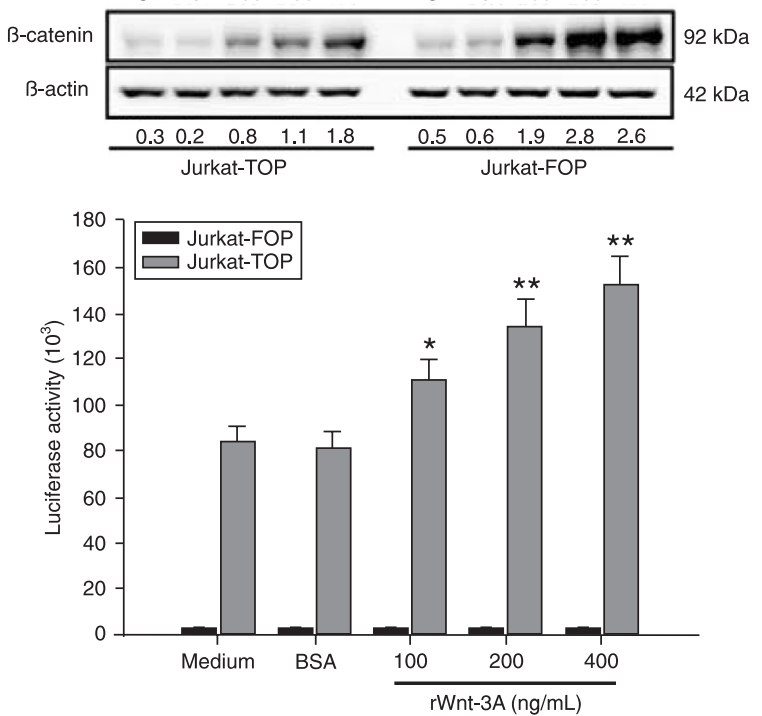

B $\quad \mathrm{BIO}(\mu \mathrm{M}) \quad \mathrm{BIO}(\mu \mathrm{M})$
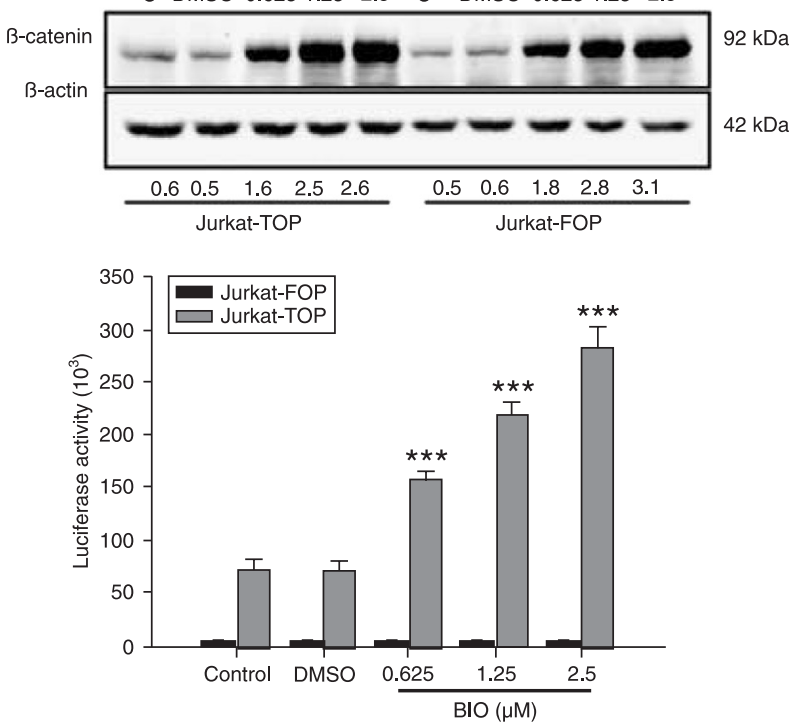

C
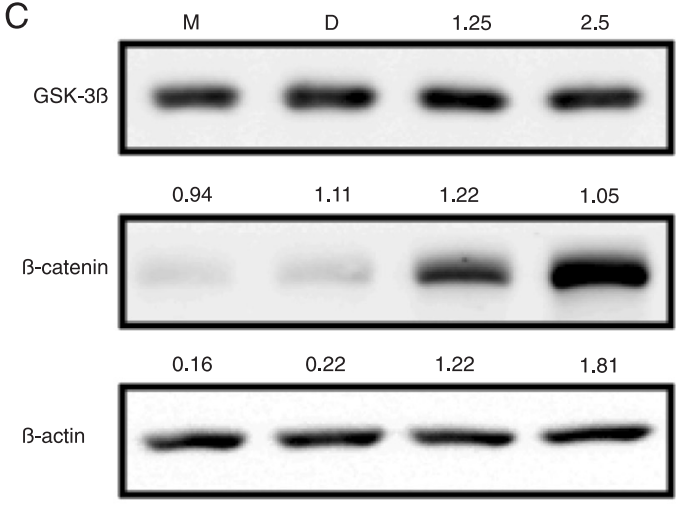

Figure 4. Induction of $\beta$-catenin protein and luciferase activity in Jurkat-TOP stable cells by rWnt-3A and BIO. Jurkat-TOP/FOP cells ( 2 x 104) were seeded into a 96-well plate for $24 \mathrm{~h}$ and then treated with (A) 100,200 , and $400 \mathrm{ng} / \mathrm{mL} \mathrm{rWnt}-3 \mathrm{~A}$ or $(\mathrm{B}$ and $\mathrm{C}) 0.625,1.25$, and $2.5 \mu \mathrm{M}$ BIO for 24 and $12 \mathrm{~h}$, respectively. Total cell proteins were collected and subjected to Western blotting and to the luciferase assay. The ratios of $\beta$-catenin or GSK-3 $\beta$ to $\beta$-actin proteins are shown in the bottom panel. BIO = (2'Z,3'E)-6-bromoindirubin-3'-oxime. ${ }^{*} \mathrm{P}<0.05,{ }^{* *} \mathrm{P}<0.01$ vs cells treated with BSA. ${ }^{* *} \mathrm{P}<0.001$ vs cells treated with DMSO (Student $t$-test). Lane M = medium; lane $\mathrm{D}=$ DMSO.

$\mu \mathrm{M})$, repressed about $62 \%$ of luciferase activity in the cells. These data suggested that NCTD affected Wnt/ $\beta$-catenin signaling by inhibition of $\beta$-catenin or its downstream pathway. Additionally, the effects of NCTD on Jurkat cell proliferation were determined by ${ }^{3} \mathrm{H}$-thymidine uptake. As shown in Figure 5B, the proliferation of Jurkat cells was not affected by DMSO, but 25 and $50 \mu \mathrm{M}$ NCTD inhibited cell proliferation in a dose-dependent manner $(P<0.001)$.

To determine whether NCTD inhibition of Jurkat cell proliferation was related to $\mathrm{Wnt} / \beta$-catenin signaling, we determined the levels of $\beta$-catenin protein in Jurkat cells.
As shown in Figure 6A, Western blot analysis demonstrated that NCTD reduced the levels of $\beta$-catenin protein present in Jurkat cells in a dose-dependent manner. However, NCTD did not affect $\beta$-catenin mRNA expression in Jurkat cells (Figure 6B). These results suggest that the reduction of Jurkat cell proliferation induced by NCTD might be related to blocking of the $\mathrm{Wnt} / \beta$-catenin signaling pathway.

\section{Discussion}

The Wnt/ $\beta$-catenin signaling pathway has been con- 


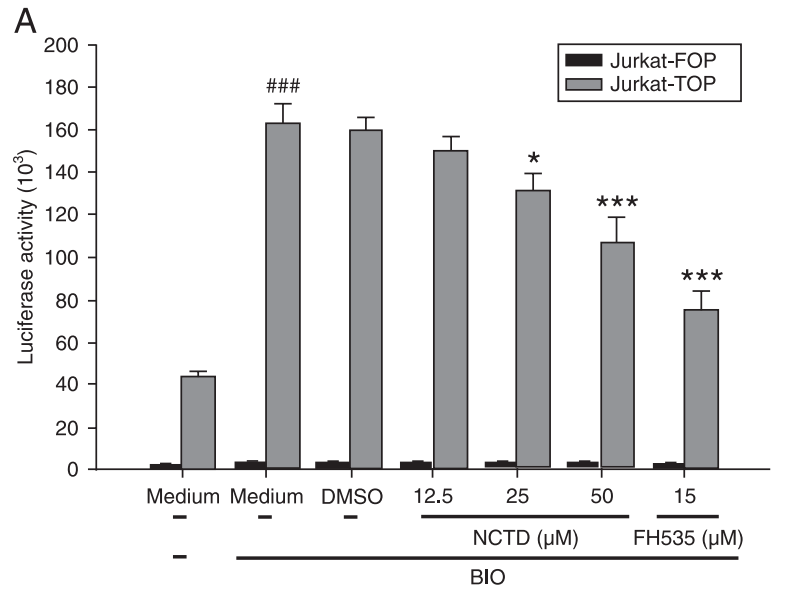

B

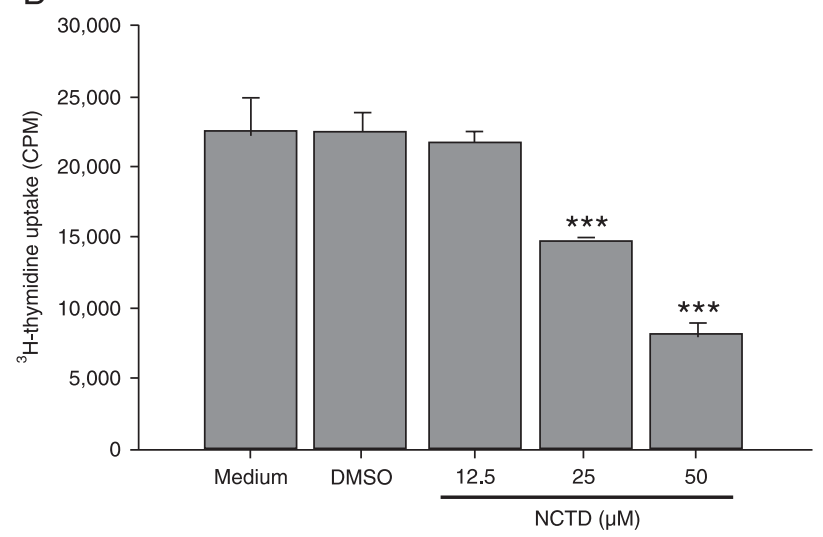

Figure 5. NCTD decreased luciferase activity in Jurkat-TOP cells induced by $\mathrm{BIO}$ and reduced Jurkat cell proliferation. Jurkat-TOP/ FOP cells $\left(2 \times 10^{4} /\right.$ well $)$ were plated into a 96 -well plate for $24 \mathrm{~h}$ and then stimulated with $\mathrm{BIO}(2.5 \mu \mathrm{M})$ in the presence of NCTD $(25$ and $50 \mu \mathrm{M})$ or a positive inhibitor (FH535, $15 \mu \mathrm{M})$ for $12 \mathrm{~h}$. Total cell proteins were quantified and subjected to the luciferase assay. Each bar indicates the mean \pm SD of three independent experiments. \#P $<0.001$ vs cells treated with medium only. ${ }^{*} P$ $<0.05,{ }^{* * *} \mathrm{P}<0.001$ vs cells treated with $\mathrm{BIO}$ and $0.025 \%$ DMSO (Student $t$-test). B, Jurkat cells were treated with $0.1 \%$ DMSO or NCTD $(12.5,25$ and $50 \mu \mathrm{M})$ for $48 \mathrm{~h}$. Cell proliferation was assayed based on the uptake of ${ }^{3} \mathrm{H}$-thymidine. After $16 \mathrm{~h}$ of incubation, the cells were harvested with an automatic harvester onto a glass fiber and the level of radioactivity was measured with a scintillation counter. NCTD = norcantharidin; $B I O=\left(2^{\prime} Z, 3^{\prime} E\right)-6-$ bromoindirubin-3'-oxime. ${ }^{* * *} \mathrm{P}<0.001$ vs cells treated with DMSO (Student $t$-test).
A

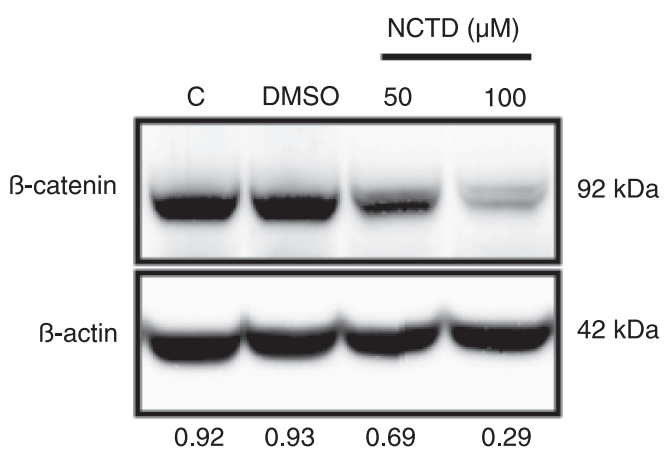

B

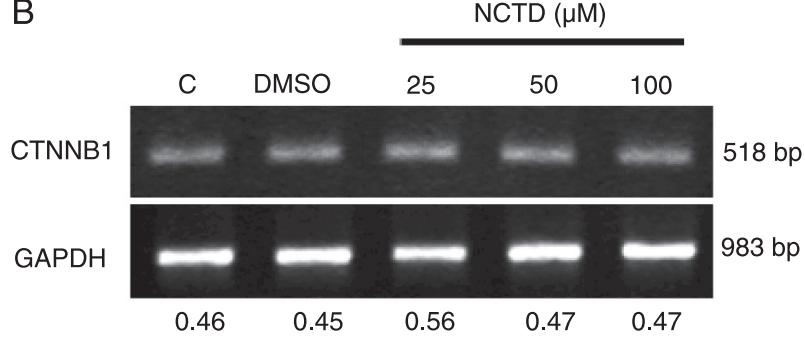

Figure 6. NCTD impaired $\beta$-catenin protein production, but did not affect mRNA expression in Jurkat cells. Jurkat cells were treated with medium (C), 0.1\% DMSO and NCTD $(25,50$ and $100 \mu \mathrm{M})$ for $24 \mathrm{~h}$. The levels of $\beta$-catenin proteins $(A)$ and transcripts $(B)$ were measured by Western blotting and RT-PCR, respectively. The numbers at the bottom indicate the ratio of $\beta$-catenin protein and mRNA to $\beta$-actin and GAPDH, respectively. NCTD = norcantharidin. 
sidered to be a new target for oncology drug discovery (21). Combining treatment with a Wnt/ $\beta$-catenin signaling pathway inhibitor and conventional anti-cancer therapy might be effective in stimulating tumor regression. In order to establish a more convenient and efficient drug screening platform, in the present study we developed an HEK 293TOP stable cell line that included a Wnt/ $\beta$-catenin signaling reporter plasmid. The luciferase activity of the HEK 293-TOP stable clone was activated by rWnt-3A, Wnt-3A CM, and a GSK-3 $\beta$ inhibitor and this effect was inhibited by a positive control, aspirin. Using this stable clone as a drug-screening platform, we first proved that NCTD not only inhibited rWnt-3A induction of the $\beta$-catenin/LEF signaling pathway but also decreased the levels of $\beta$-catenin protein and cell proliferation in Jurkat cells. The present study describes a stable cell line that could be used for the screening of anti-Wnt/ $\beta$-catenin signaling agents.

The methods for anti-Wnt/ $\beta$-catenin drug screening have been developed using different systems. The ELISAbased model limits the functional testing of the candidate drug to the $\beta$-catenin/TCF complex (10). However, the commercially available reporter plasmids for detecting $\mathrm{Wnt} / \beta$-catenin signaling require transient transfection of the plasmid before drug screening. This is not only time- and reagent-consuming, but the transfection efficiency also varies from experiment to experiment. To solve these problems, a stable clone needs to be established by co-transfecting reporter- and antibiotic-containing plasmids $(20,22,23)$. In the present study, we successfully established stable clone HEK 293-TOP cells that contained a bi-functional reporter plasmid. This design could solve the problem caused by co-transfection of a selection marker. When the latter approach is used, the drug-resistant cells that survive might lose the reporter plasmid during long-term culture and this will result in weaker luciferase signaling. During the cloning process of the $3 X$ LEF/TCF binding sites into the pGL4.3 plasmid, our initial construct was unsuccessful even though we tried $3 X$ LEF/TCF binding sequences created by nucleotide synthesis or by PCR amplification. We thought that this failure might be due to the unusual secondary DNA structures, such as hairpins and cruciforms (24). Indeed, computer modeling on the DINAMelt Server suggested that the full length of the $3 X$ LEF/TCF binding sites formed a single hairpin structure (data not shown). To solve this problem, the primer set (TOP-F265 and TOP-R265), upstream and downstream of $3 X$ LEF/TCF, was designed to amplify the TOP elements, which contain $3 X$ LEF/TCF binding sites while creating linear forms of DNA at each end. Finally, we were able to successfully amplify the TOP (or FOP) elements from TOPFLASH (or FOPFLASH) and insert them into a pGL4.3 reporter plasmid. After long-term antibiotic selection, HEK 293-TOP and HEK 293-FOP stable cells were chosen.

The luciferase gene in HEK 293-TOP cells could be significantly induced by rWnt-3A and Wnt-3A CM. Binnerts et al. (25) reported a similar result when they stimulated cells with serial concentrations of rWnt-3A. In addition, whether the HEK 293-TOP cells specifically responded to canonical Wnt/ $\beta$-catenin signaling was also examined in this study. Two GSK-3 $\beta$ inhibitors $\mathrm{LiCl}$ and $\mathrm{BIO}$, which are able to increase $\beta$-catenin stability and induce $\beta$-catenin nuclear translocation (26), were used in this study. $\mathrm{LiCl}$ competes for the cofactor $\mathrm{Mg}^{2+}$ and blocks GSK-3 $\beta$ kinase activity, while BIO selectively binds to the ATP binding pocket of the kinase and inhibits enzyme activity (26). Our results with HEK 293-TOP showed that luciferase activity increased in the presence of $\mathrm{BIO}$ or $\mathrm{LiCl}$. Each of these drugs had an additive effect with rWnt-3A. When we investigated an HEK 293-FOP clone with mutant LEF/TCF binding sites, our results showed that Wnt-3A CM was not able to induce luciferase activity in HEK 293-FOP cells (Figure 2A). Therefore, we confirmed that the luciferase expression in HEK 293-TOP cells induced by rWnt-3A or Wnt-3A CM was LEF/ TCF-dependent and came specifically from the canonical Wnt/ $\beta$-catenin signaling pathway.

Small molecules have been shown to have a wide range of biological activities and this has been confirmed in clinical trials (27). In the present study, we showed that aspirin decreased rWnt-3A-induced luciferase activity, in agreement with Cho et al. (19). Recently, we measured the effect of aspirin (5 mM) on HEK 293-TOP cell growth by Trypan blue staining. Preliminary data demonstrated that aspirin did not increase cell death but delayed cell proliferation. Compared to the untreated control, from day 1 to day 3 , the rates of aspirin inhibition of cell growth were 24,26 , and $47 \%$, respectively. We, therefore, identified small molecules with anti-Wnt/ $\beta$-catenin activity by the HEK 293-TOP reporter assay, including norcantharidin, a demethylated form of cantharidin derived from blister beetles (28). In this study, we found that $50 \mu \mathrm{M}$ NCTD showed a positive result and decreased the luciferase activity of the HEK 293-TOP and Jurkat-TOP cells that had been induced by Wnt-3A or BIO (Figures 3C,D and Figure 5A). Although the luciferase activity was slightly decreased in HEK 293-FOP cells after treatment with $100 \mu \mathrm{M}$ NCTD, this might have been a result of cytotoxicity (Figure $3 \mathrm{C}$ ). This high dosage decreased cell numbers by about $25-30 \%$ as determined by the MTT assay. In addition to inhibiting Wnt-3A-induced luciferase activity, NCTD also suppressed the proliferation of human acute leukemia Jurkat cells and reduced the level of $\beta$-catenin protein in these cells. It has been reported that Jurkat cells express a higher level of $\beta$-catenin than normal resting peripheral blood mononuclear cells and NCTD inhibits Jurkat cell proliferation. Our results were consistent with those reported by Liao et al. (29), which showed that NCTD had a greater inhibitory effect on Jurkat cells. However, the anti-proliferation effect of 25 $\mu \mathrm{M}$ NCTD was not correlated with the luciferase assay. We suggest that NCTD has different mechanisms of cell growth inhibition (30), which, however, partially occur through the 
Wnt/ $\beta$-catenin signaling pathway. The study by Liao et al. (29) shows that treatment of Jurkat cells with NCTD for 24 or $48 \mathrm{~h}$ increases the sub-G1 DNA content and the active form of the caspase- 9 and -3 protein levels, thus causing cell apoptosis. In the present study, we indicated that Jurkat cell proliferation was blocked after treatment with NCTD for 48 h. We could not exclude the possibility of NCTD causing cell apoptosis. It is well known that the $\mathrm{N}$-terminus of $\beta$-catenin (Ser33/Ser37/Thr41) is phosphorylated by GSK-3 $\beta$ and then targeted for ubiquitin-dependent degradation. Although mutation at the $\mathrm{N}$-terminus of $\beta$-catenin has been found in some tumors, mutations at these sites have not been found in Jurkat cells (20). NCTD has been reported to inhibit protein phosphatase 2A (PP2A) activity and PP2A has been found to positively control Wnt/ $\beta$-catenin signaling upon Wnt stimulation $(31,32)$. In this context, inhibition of PP2A will promote $\beta$-catenin phosphorylation and degradation. The result shown in Figure 6 further supports our suggestion that NCTD affects $\beta$-catenin in terms of protein regulation rather than transcription. However, the detailed mechanism of action of NCTD remains to be elucidated.

\section{References}

1. Ysebaert L, Chicanne G, Demur C, De Toni F, Prade-Houdellier N, Ruidavets JB, et al. Expression of beta-catenin by acute myeloid leukemia cells predicts enhanced clonogenic capacities and poor prognosis. Leukemia 2006; 20: 12111216.

2. Groen RW, Oud ME, Schilder-Tol EJ, Overdijk MB, ten Berge $D$, Nusse $R$, et al. Illegitimate WNT pathway activation by beta-catenin mutation or autocrine stimulation in T-cell malignancies. Cancer Res 2008; 68: 6969-6977.

3. Simon M, Grandage VL, Linch DC, Khwaja A. Constitutive activation of the $\mathrm{Wnt} /$ beta-catenin signalling pathway in acute myeloid leukaemia. Oncogene 2005; 24: 2410-2420.

4. Ishii $\mathrm{H}$, Iwatsuki $M$, leta $\mathrm{K}$, Ohta $\mathrm{D}$, Haraguchi $\mathrm{N}$, Mimori $\mathrm{K}$, et al. Cancer stem cells and chemoradiation resistance. Cancer Sci 2008; 99: 1871-1877.

5. Jamieson $\mathrm{CH}$, Ailles LE, Dylla SJ, Muijtjens M, Jones C, Zehnder JL, et al. Granulocyte-macrophage progenitors as candidate leukemic stem cells in blast-crisis CML. N Engl J Med 2004; 351: 657-667.

6. Li C, Heidt DG, Dalerba P, Burant CF, Zhang L, Adsay V, et al. Identification of pancreatic cancer stem cells. Cancer Res 2007; 67: 1030-1037.

7. Malanchi I, Peinado H, Kassen D, Hussenet T, Metzger D, Chambon $\mathrm{P}$, et al. Cutaneous cancer stem cell maintenance is dependent on beta-catenin signalling. Nature 2008; 452 : 650-653.

8. O'Brien CA, Pollett A, Gallinger S, Dick JE. A human colon cancer cell capable of initiating tumour growth in immunodeficient mice. Nature 2007; 445: 106-110.

9. Dihlmann S, Klein S, Doeberitz Mv MK. Reduction of betacatenin/T-cell transcription factor signaling by aspirin and indomethacin is caused by an increased stabilization of phosphorylated beta-catenin. Mol Cancer Ther 2003; 2:
In the present study, a new Wnt/ $\beta$-catenin signaling response reporter plasmid, pGL4-TOP/FOP, was used to establish HEK 293-TOP/FOP and Jurkat-TOP/FOP stable clones. Using this platform, we discovered that NCTD inhibited Wnt-3A-induced Wnt/ $\beta$-catenin signaling and suppressed proliferation of $\beta$-catenin-dependent Jurkat cells. Taken together, these results show that the HEK 293-TOP stable clone can be seen as a convenient platform for high-throughput drug screening and could be applied to the screening of anti-tumor drugs that interrupt the Wnt/ $\beta$ catenin signaling pathway.

\section{Acknowledgments}

We thank Dr. Chia-Ning Shen for providing the $L$ Wnt-3A cells. Research partially supported by grants-in aid from Fu-Jen University (\#9991A15/10963104995-4; \#9991A15/10973104995-4), The National Science Council (NSC96-2320-B-030-006-MY3), Committee on Chinese Medicine and Pharmacy (CCMP96-RD-207), and Council of Agriculture, Republic of China (\#97-1.2.1-a1-22).

509-516.

10. Lepourcelet M, Chen YN, France DS, Wang $H$, Crews $P$, Petersen F, et al. Small-molecule antagonists of the oncogenic Tcf/beta-catenin protein complex. Cancer Cell 2004; 5: 91-102.

11. Emami KH, Nguyen $\mathrm{C}$, Ma H, Kim DH, Jeong KW, Eguchi $\mathrm{M}$, et al. A small molecule inhibitor of beta-catenin/CREBbinding protein transcription [corrected]. Proc Natl Acad Sci U S A 2004; 101: 12682-12687.

12. Brembeck FH, Rosario M, Birchmeier W. Balancing cell adhesion and Wnt signaling, the key role of beta-catenin. Curr Opin Genet Dev 2006; 16: 51-59.

13. Kikuchi A, Kishida S, Yamamoto H. Regulation of Wnt signaling by protein-protein interaction and post-translational modifications. Exp Mol Med 2006; 38: 1-10.

14. He TC, Sparks AB, Rago C, Hermeking H, Zawel L, da Costa $\mathrm{LT}$, et al. Identification of C-MYC as a target of the APC pathway. Science 1998; 281: 1509-1512.

15. Tetsu O, McCormick F. Beta-catenin regulates expression of cyclin D1 in colon carcinoma cells. Nature 1999; 398: 422426.

16. Chen YC, Chang SC, Wu MH, Chuang KA, Wu JY, Tsai WJ, et al. Norcantharidin reduced cyclins and cytokines production in human peripheral blood mononuclear cells. Life Sci 2009; 84: 218-226.

17. Barolo S. Transgenic Wnt/TCF pathway reporters: all you need is Lef? Oncogene 2006; 25: 7505-7511.

18. Hedgepeth CM, Conrad LJ, Zhang J, Huang HC, Lee VM, Klein PS. Activation of the Wnt signaling pathway: a molecular mechanism for lithium action. Dev Biol 1997; 185: 82-91.

19. Cho M, Gwak J, Park S, Won J, Kim DE, Yea SS, et al. Diclofenac attenuates $\mathrm{Wnt} /$ beta-catenin signaling in colon 
cancer cells by activation of NF-kappaB. FEBS Lett 2005; 579: 4213-4218.

20. Chung EJ, Hwang SG, Nguyen P, Lee S, Kim JS, Kim JW, et al. Regulation of leukemic cell adhesion, proliferation, and survival by beta-catenin. Blood 2002; 100: 982-990.

21. Janssens N, Janicot M, Perera T. The Wnt-dependent signaling pathways as target in oncology drug discovery. Invest New Drugs 2006; 24: 263-280.

22. Park S, Gwak J, Cho M, Song T, Won J, Kim DE, et al. Hexachlorophene inhibits Wnt/beta-catenin pathway by promoting Siah-mediated beta-catenin degradation. Mol Pharmacol 2006; 70: 960-966.

23. Suzuki A, Ozono K, Kubota T, Kondou H, Tachikawa K, Michigami T. PTH/cAMP/PKA signaling facilitates canonical Wnt signaling via inactivation of glycogen synthase kinase-3beta in osteoblastic Saos-2 cells. J Cell Biochem 2008; 104: 304317.

24. Kirschner LS. De novo generation of simple sequence during gene amplification. Nucleic Acids Res 1996; 24: 28292834.

25. Binnerts ME, Kim KA, Bright JM, Patel SM, Tran K, Zhou $\mathrm{M}$, et al. R-Spondin1 regulates Wnt signaling by inhibiting internalization of LRP6. Proc Natl Acad Sci U S A 2007; 104: 14700-14705.

26. Meijer L, Skaltsounis AL, Magiatis P, Polychronopoulos P,
Knockaert M, Leost M, et al. GSK-3-selective inhibitors derived from Tyrian purple indirubins. Chem Biol 2003; 10: 1255-1266.

27. Efferth T, Li PC, Konkimalla VS, Kaina B. From traditional Chinese medicine to rational cancer therapy. Trends $\mathrm{Mol}$ Med 2007; 13: 353-361.

28. Tsauer W, Lin JG, Lin PY, Hsu FL, Chiang HC. The effects of cantharidin analogues on xanthine oxidase. Anticancer Res 1997; 17: 2095-2098.

29. Liao HF, Su SL, Chen YJ, Chou CH, Kuo CD. Norcantharidin preferentially induces apoptosis in human leukemic Jurkat cells without affecting viability of normal blood mononuclear cells. Food Chem Toxicol 2007; 45: 1678-1687.

30. Huang Y, Liu Q, Liu K, Yagasaki K, Zhang G. Suppression of growth of highly-metastatic human breast cancer cells by norcantharidin and its mechanisms of action. Cytotechnology 2009; 59: 201-208.

31. Hart ME, Chamberlin AR, Walkom C, Sakoff JA, McCluskey A. Modified norcantharidins; synthesis, protein phosphatases 1 and $2 \mathrm{~A}$ inhibition, and anticancer activity. Bioorg Med Chem Lett 2004; 14: 1969-1973.

32. Eichhorn PJ, Creyghton MP, Bernards R. Protein phosphatase $2 A$ regulatory subunits and cancer. Biochim Biophys Acta 2009; 1795: 1-15. 